lymphocytes of one of the patients but not in bladder epithelial cells or hair. ${ }^{17}$

Effective treatment of the mitochondrial myopathies remains limited. Acute exacerbations with severe lactic acidosis precipitated by exercise, infection, or alcohol may be improved by correcting the acidosis with a slow infusion of sodium bicarbonate. Patients with carnitine deficiency associated with a respiratory chain defect may improve with oral carnitine. Ubiquinone, ascorbic acid, menadione, and steroids have all been tried with varying success. Clearer understanding of the molecular mechanisms underlying these metabolic defects may lead to more effective treatment.

ANTHONY H V SCHAPIRA

Senior Lecturer and Consultant Neurologist,

Royal Free Hospital Medical School and

Institute of Neurology,

London WCIN 3BG

1 Morgan-Hughes JA. Mitochondrial disease. Trends Neurosci 1986;9:15-9.

2 Di Mauro S, Bonilla E, Zeviani M, Nakagawa H, De Vivo DC. Mitochondrial myopathies. Ann Neurol 1985;17:521-38.

3 Morgan-Hughes JA, Cooper JM, Schapira AHV, Hayes DJ, Clarke JB. The mitochondrial myopathies. Defects of the mitochondrial respiratory chain and oxidative phosphorylation myopathies. Defects of the mitochondrial respiratory chain and oxidative phosphorylation encephalography and clinical neurophysiology. Suppl 39. Amsterdam: Elsevier Science Publishers, 1987:103-14.

4 Chomyn A, Mariottini P, Cleeter MWJ, et al. Functional assignment of the unidentified reading frames of human mitochondrial DNA. In: Quagliariello E, Slater EC, Palmieri F, Saccone C, Kroon AM, eds. Achievements and perspectives of mitochondrial research. Vol II. Amsterdam Elsevier Science Publishers, 1985:259-75.

5 Rosing HS, Hopkins LC, Wallace DC, Epstein CM, Widenheim K. Maternally inherited mitochondrial myopathy and myoclonic epilepsy. Ann Neurol 1985;17:228-37.

6 Harding AE, Petty RKH, Morgan-Hughes JA. Mitochondrial myopathy: a genetic study of 71 cases. $\mathcal{J}$ Med Genet 1988;25:528-35.

7 Petty RKH, Harding AE, Morgan-Hughes JA. The clinical features of mitochondrial myopathy. Brain 1986;109:915-38.

8 Morgan-Hughes JA, Hayes DJ, Clark JB, et al. Mitochondrial encephalomyelopathies: biochemical studies in two cases revealing defects in the respiratory chain. Brain 1982;105: 553-82.

9 Frackowiak RSJ, Herold S, Petty RKH, Morgan-Hughes JA. The cerebral metabolism of glucose and oxygen measured with positron tomography in patients with mitochondrial diseases. Brain 1988;111:1009-24.

10 Kuhn-Nentwig L, Kadenbach B. Isolation and properties of cytochrome c oxidase from rat liver and quantification of immunological differences between isoenzymes from various rat tissues and quantification of immunological differences between isoen
with subunit specific antisera. Eur $\mathcal{F}$ Biochem 1985;149:147-58.

11 Clay VJ, Ragan CI. Evidence for the existence of tissue-specific isoenzymes of mitochondrial NADH dehydrogenase. Biochem Biophys Res Commun 1988;157:1423-8.
NAD

12 Schapira AHV, Cooper JM, Morgan-Hughes JA, et al. Molecular basis of mitochondrial myopathies: polypeptide analysis in complex I deficiency. Lancet 1988; i:500-3.

13 Schapira AHV, Cooper JM, Morgan-Hughes JA, Landon DN. A mitochondrial myopathy with specific deficiency of succinate dehydrogenase activity and the Rieske FeS protein of complex III. Neuropathol Appl Neurobiol 1987;13:497.

14 Holt IJ, Harding AE, Morgan-Hughes JA. Deletions of mitochondrial DNA in patients with mitochondrial myopathy. Nature 1988;331:717-9.

15 Holt IJ, Cooper JM, Morgan-Hughes JA, Harding AE. Deletions of muscle mitochondrial DNA. Lancet 1988 ; i: 1462 .

16 Zeviani M, Moraes CT, Di Mauro S, et al. Deletions of mitochondrial DNA in Kearns-Sayre syndrome. Neurology 1988;38:1339-46.

17 Poulton J, Deadman ME, Gardiner RM. Duplications of mitochondrial DNA in mitochondrial myopathy. Lancet 1989;i:236-40.

\title{
NHS review: the first three months
}

\section{Time for the posturing to stop}

Much of the style and content of the government's white paper on the NHS was bound to provoke antagonism. ${ }^{1}$ Firstly, the timetable requiring the first hospital trusts and budget holding practices to be operational by the end of 1991 is widely regarded as all but impossible. It permits no time for evaluative studies or demonstration projects. Secondly, the government's apparent determination to impose the full set of changes on a reluctant service is abrasive and confrontational. By defending the white paper hook, line, and sinker the government has failed to allow the service to respond to the positive features while seeking further clarification of the more questionable elements.

Thirdly, the vagueness of many of the white paper's proposals does not encourage the belief that their consequences have been carefully anticipated and approved. The absurdly fine detail in which the valuation of capital assets has been described (requiring, for example, the separate valuation of every individual item above $£ 1000$ ) emphasises the paucity of detail supporting innovative proposals such as creating hospital trusts and pricing and selling services. Virtually nothing has been said about the implications of these profound changes for community care, medical manpower planning and training, strategic planning of health care services, management and accounting costs, or pursuit of social and geographical equity in health care. Nowhere has it been explained exactly how patients will have a greater choice of health care at no less inconvenience than at present. All that has been offered are broad assurances that all will be well.

Beneath the justifiable demands for detailed answers to questions such as these are deeper fears about long term objectives and implications. The white paper is to be understood as a political statement, not as a planning document; it seeks to apply to health care many of the principles of change that are being implemented throughout the public sector services. Its effect will be to destabilise the
NHS, a process that may be intensified through government policies for the future funding of the service. Although the review was set up amid widespread fears about the underfunding of the NHS, the white paper offers no prospect of change in either the level or the source of funds. Indeed, the 1989 Public Expenditure White Paper, ${ }^{2}$ published the day before the white paper, forecast annual increases in total NHS expenditure of only $7 \cdot 7 \%, 5 \cdot 3 \%$, and $4 \cdot 2 \%$ respectively over the next three years. These figures do not allow for inflation, nor do they take account of demographic or technological changes. Circumstances could easily arise (such as the continuation of high inflation) in which these figures would become real cuts.

The destabilisation of the NHS, the absence of increased expenditure, and the introduction of the principle of tax relief on private health insurance premiums have fuelled fears that the proposals are an interim step towards privatisation. Although any such intent has been denied by Mr Clarke, the fear is reasonable. The government believes in the power of market forces to produce an efficient allocation of goods and services, and it has implemented that belief in public services that 10 years ago almost nobody thought could be privatised. There is no reason why this long term political programme should stop short at the NHS.

It is regrettable, however, that the intense hostility engendered by the white paper has obstructed much real debate about its meritorious features. That the hostility has spilt over to the proposed new contract for general practitioners has exacerbated the tendency to simplify and polarise opinion, as though there are no midway points between an uncritical belief in the rightness of the government's proposals and an implacable opposition to every last detail.

Several features of the white paper do reflect and develop ideas that have been discussed for some time and that until 
recently were regarded as reasonable ways of tackling some of the problems that plainly exist in the NHS. Introducing medical audit, developing better information systems, devolving budgets to doctors whose decisions commit the expenditure of public money, revising the element of cross boundary flows in the RAWP (Resource Allocation Working Party) formula, searching for ways of rewarding rather than penalising productive hospitals, and controlling excessive prescribing are all activities that have been debated for some time, and most have been issues in which doctors have been prominent in pushing for change. The white paper's proposals in these matters may not be sufficiently detailed or wholly practicable, but there should be debate about their merits as instruments of change.

Thus it would be wrong to reject parts of the white paper that are merely building on trends already underway without making alternative suggestions for tackling the important problems they deal with, although the service has not been encouraged to respond critically and selectively to different proposals. But the government should also recognise why its white paper has aroused such antagonism and seek to answer its critics with detailed evidence and argument rather than bland reassurance. The central notion of the internal market might be made to work for the benefit of patients in certain circumstances, but the evidence-for example, from a series of demonstration projects - needs to be assembled before its national introduction. It is with the aim of raising the debate that the $B M F$ has published the series of articles that concludes today. (The series is to be published as a book that will be available by 8 May.) Perhaps the time has come for the posturing to stop and the detailed discussions to start. Otherwise the NHS and those whom it serves may become victims of the verbal cross fire.

J R BUTLER

Professor of Health Services Studies,

University of Kent at Canterbury,

Canterbury,

Kent CT2 7NF

1 Secretaries of State for Health, Wales, Northern Ireland, and Scotland. Working for patients. London: HMSO, 1989. (Cmnd 555.)

2 HM Treasury. The government's expenditure plans 1989-90 to 1991-92. London: HMSO, 1989. (Cmnd 614.)

\section{Overuse injuries in musicians}

\section{Although they cause much distress, their aetiology and treatment remain controversial}

Musicians suffer from all sorts of occupational ills, many of them well documented. Schumann's hand injury, possibly neurological, caused him to concentrate on composition. 'The remarkable laxity of Paganini's hand, possibly due to a hereditary connective tissue abnormality, gave him a technical advantage over his contemporaries. ${ }^{2}$ And there have been diverting accounts of cor anglais player's thumb, cymbal player's shoulder, pianist's cramp, and horn player's palsy. ${ }^{3}$

Nevertheless, delightful as they are, these case reports have diverted attention from the commonest complaint of many musicians: the repetitive overuse syndrome. This has been extensively described in Australia ${ }^{+6}$ but the problem occurs all over the world. Thus similar reports have come from special music clinics in the United States (P H Caldron et al, abstract to scientific meeting of the American Rheumatism Association, 1985) ${ }^{7}$ and from a study of eight orchestras from several countries, where the findings were uniform and independent of national bias. ${ }^{8}$ Clinical grading may be applied to the overuse syndrome. ${ }^{+}$Features vary from grade 1 (pain at one site on activity) through increasing degrees of disability to grade 5 (loss of capacity to use because of continuous pain associated with loss of muscle function). The treatment differs little from that initially recommended by Poore in 1887 on the basis of a careful study of 21 pianists with symptoms in the hands and wrists that he attributed to muscular strain. ${ }^{9} \mathrm{~A}$ central feature of treatment is "rest," but does this mean a simple change in technique or complete abstinence from movement? Poore's comment that "directly they feel in a small degree better, they fly to the piano" reflects the reaction of most musicians today as it did then. Reassurance, a sympathetic ear, and sometimes treatment with anxiolytics or $\beta$ blockers have all been advocated.

The cause of the overuse syndrome in musicians remains controversial. Although some music students have been found to have laxer joints than others ${ }^{10}$ such a difference probably accounts for only a fraction of the problem. ${ }^{11}$ Other factors may be the dominance of one side, giving an asymmetry in muscle weight, ${ }^{12}$ and fatigability. ${ }^{13}$ Different patterns of symptoms are caused by different instruments, and players may act as their own controls, particularly when, as in string players, the function of the two arms is different..$^{14}$ A recent study compared biopsy findings in the first dorsal interosseous muscle in 29 women with the painful chronic overuse syndrome with those in the same muscle from eight volunteer controls. ${ }^{15}$ Patients with the overuse syndrome all showed an increase in type 1 fibres with type grouping, decreased and hypertrophied type 2 fibres, and an increased number of nuclei and mitochondria. Such changes were different from those seen in disuse atrophy, though ethical considerations made it impossible to study a group of patients or musicians who were performing identical work without developing the overuse syndrome. Some neurologists have attributed almost half of the complaints to "inflammatory disorder of the tendons"; ; rheumatologists, less convinced that synovial proliferation is present, have preferred to draw an analogy to the focal dystonia of writer's cramp. ${ }^{16}$ Smythe believes that all the repetitive strain syndrome in the arm is referred pain from the neck. ${ }^{17}$ Others have suggested that hyperventilation ${ }^{18}$ or even anxiety is the cause, given that the syndrome can be exacerbated by stress. Nevertheless, characteristically the symptoms can be induced by a particular repetitive technical task and are relieved by rest, only to return when the technique is repeated-findings that strongly support a mechanical aetiology, at least as an initiating event.

Recently the repetitive strain syndrome in non-musicians has reached epidemic proportions in Australia. ${ }^{1920}$ The workers' compensation system allows payments of a lump sum for such a work related disease, and patients have an obvious financial benefit in getting the diagnosis established; thus the cost of repetition strain injury in Australia is now estimated to be over $\$ A 1$ billion. The resultant turmoil in the courts has led the Royal Australasian College of Physicians to advocate using the term "regional pain syndrome." ${ }^{21}$ Clearly, physiological, pathological, psychological, and psychosocial 